www.jmscr.igmpublication.org

Impact Factor (SJIF): 6.379

Index Copernicus Value: 71.58

ISSN (e)-2347-176x ISSN (p) 2455-0450

crossref DOI: _https://dx.doi.org/10.18535/jmscr/v6i4.03

Journal Of Medical Science And Clinical Research

\title{
Syphilitic aortic arch aneurysm involving left lung- surgical complication and its management
}

\author{
Authors \\ Girish Gowda S L ${ }^{1 *}$, MCh, Seetharama Bhat $\mathbf{P ~ S}^{2}$, MCh, C N Manjunath ${ }^{3}$, DM \\ ${ }^{1}$ Associate Professor, Department of Cardiothoracic and Vascular Surgery \\ ${ }^{2}$ Professor and Unit Chief, Department of Cardiothoracic and Vascular Surgery \\ ${ }^{3}$ Director, Professor and Head of the Department, Department of Cardiology \\ Sri Jayadeva Institute of Cardiovascular Sciences and Research, INDIA \\ Corresponding Author \\ Dr Girish Gowda $\mathbf{S} \mathbf{L}$
}

Department of Cardiothoracic and Vascular Surgery, Sri Jayadeva Institute of Cardiovascular Sciences and

Research, Bangalore, Karnataka, pin-560069, INDIA

Contact number- +919449046932, Email: gowda1212@yahoo.co.in

\begin{abstract}
The aortic arch aneurysms presenting with symptoms only related to involvement of lung is not very uncommon. We present a case of syphilitic aortic arch aneurysm presenting with history of haemoptysis due to involvement of upper lobe of left lung. The perioperative management of air leak and bleeding from the lung is discussed in this case report.
\end{abstract}

Keywords- aortic arch aneurysm, Syphilitic aortic aneurysm, haemoptysis, air leak.

\section{Case Report}

A 50 year old female patient came with the history of haemoptysis since one month. No other symptoms which might have been caused due to compression of mediastinal structures like, hoarseness of voice or difficulty in swallowing. On auscultation there were reduced breath sounds in left upper zone and dullness on percussion in left infra clavicular region. Serological test revealed she was TPHA positive. X-ray chest showed superior mediastinal widening and aortic aneurysm extending in to left hemithorax (figure1- Chest $\mathrm{x}$-ray showing aortic aneurysm extending in to left hemithorax). Computer tomography of chest and computer tomography aortogram showed huge saccular aortic arch aneurysm of about $15 \times 15$ centimetres (figure-2, Computer tomography showing aortic arch aneurysm). She was evaluated further and posted for surgery. The surgical plan was open the aneurysm and close itsopening from inside and do leftupper lobectomy if required. On the night before the day of surgery she had increase in frequency and quantity of haemoptysis. She was taken up for surgery. Sternotomy was done after peripheral femorofemoral cannulation and cardiopulmonary bypass (CPB).Patients temperature was cooled to $19^{0} \mathrm{C}$ with a left ventricular vent in place to prevent left ventricular distention. The aneurysm was opened under circulatory arrest at $19^{\circ} \mathrm{C}$ and clot was 
extracted from the saccular aneurysm. Cerebral protection was done by retrograde cerebral perfusion through superior vena cava. Aneurysm was found to be involving the inferolateral wall of the aortic arch extending to left hemi thorax and with dense adhesions extending intoleft upper lobe. The defect in the arch was identified and it was closed using GORTEX prosthetic patch. the plan for left upper lobectomy was differed as lung appeared normal and it would be technically difficult to do lobectomy because of dense adhesions involving the lung. Patent was adequately rewarmed and was weaned from CPB. Once the patient was weaned off CPB we noticed bleeding through the endotracheal tube and major air leak from upper lobe of left lung. We decided to manage it by nonsurgical methods. Single lumen endo tracheal tube was replaced with double lumen endo tracheal tube to prevent spillage of blood from left bronchus to right bronchus. Right lung was ventilated and left bronchial suctioning was done through double lumen endotracheal tube. Air leak and bleeding in the lung was managed with local homeostasis like covering the raw surface of lung with SURGICEL and SPONGISTON. Arterial blood gases were under normal limits during this period. Endo tracheal tube bleeding got reduced and air leak was minimal after this mentioned management steps. Postoperatively there was no air leak and Endotracheal bleed was minimal and was completely absent by 12 hours after shifting the patientto intensive care unit. She was extubated after 24 hours of ventilation and there was no haemoptysis after extubating the patient. Chest $\mathrm{x}$ ray showed cleared left upper lobe zone in first postoperative day. Patient was discharged on 9th postoperative day. CT aortogram (Figure-3-, Computer tomography showing postoperative repaired aortic arch) at one month follow-up showed successful reconstruction of aortic arch aneurysm with no evidence of recurrence of aneurysm or Pseudoaneurysm. She is doing well at 12 months follow-up.

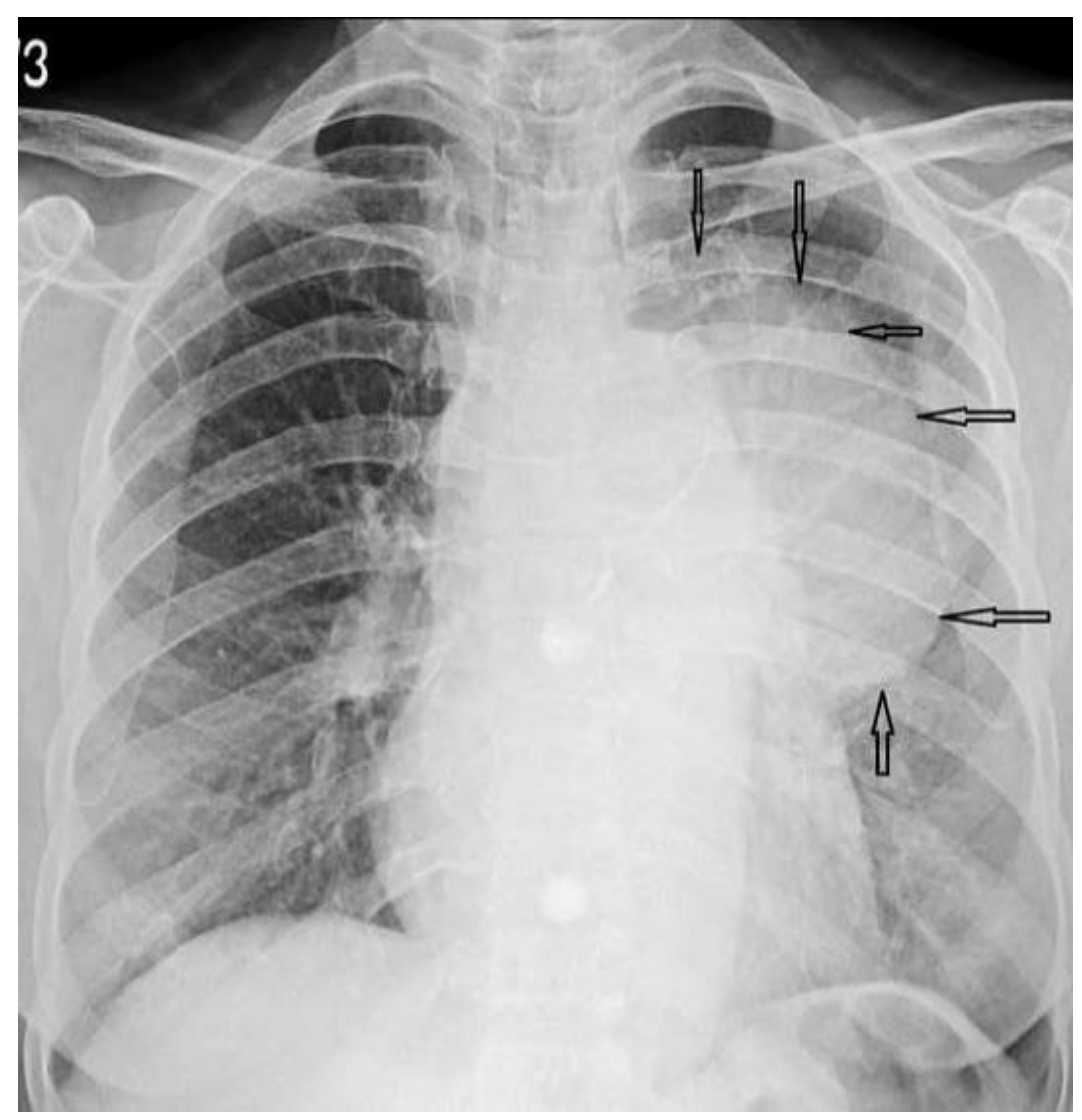

Figure-1 Chest $\mathrm{x}$-ray showing aortic aneurysm extending in to left hemithorax 


\section{JMSCR Vol||06||Issue||04||Page 18-21||April}

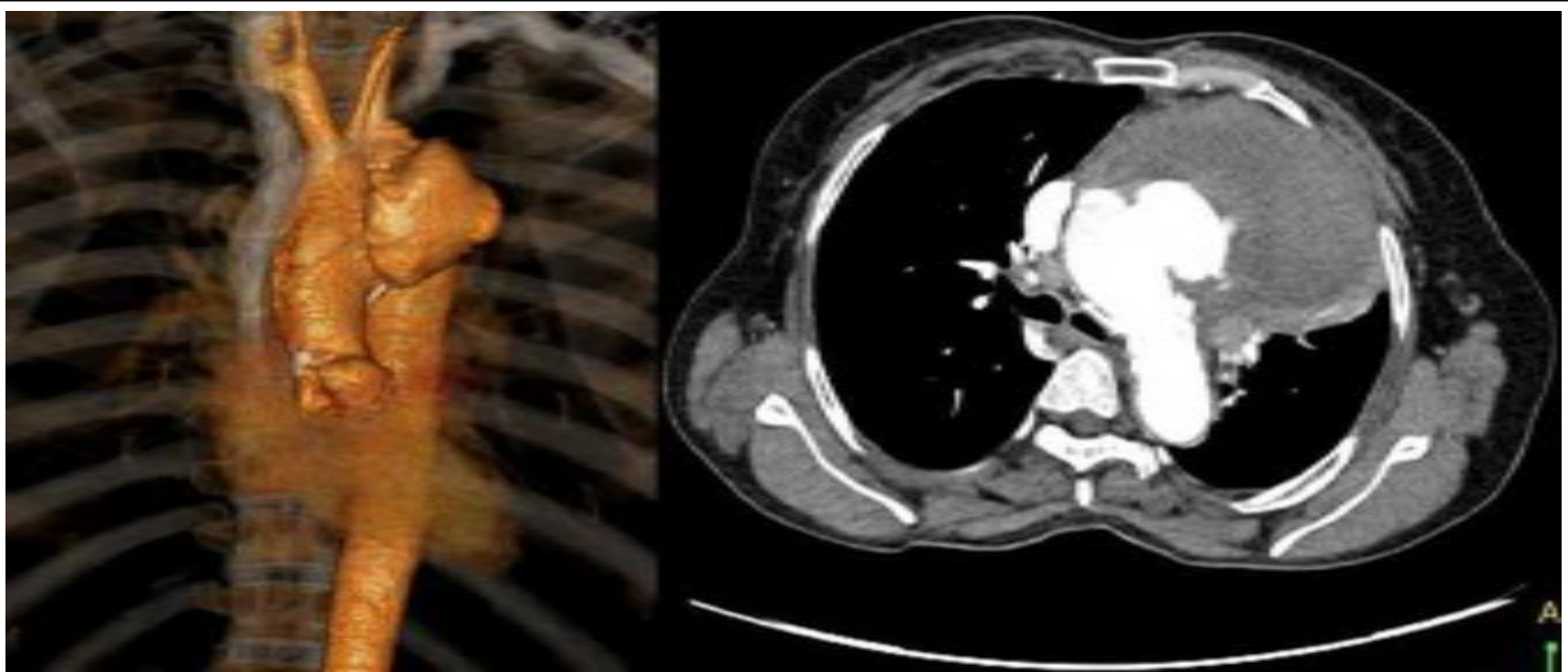

Figure-2 Computer tomography showing aortic arch aneurysm

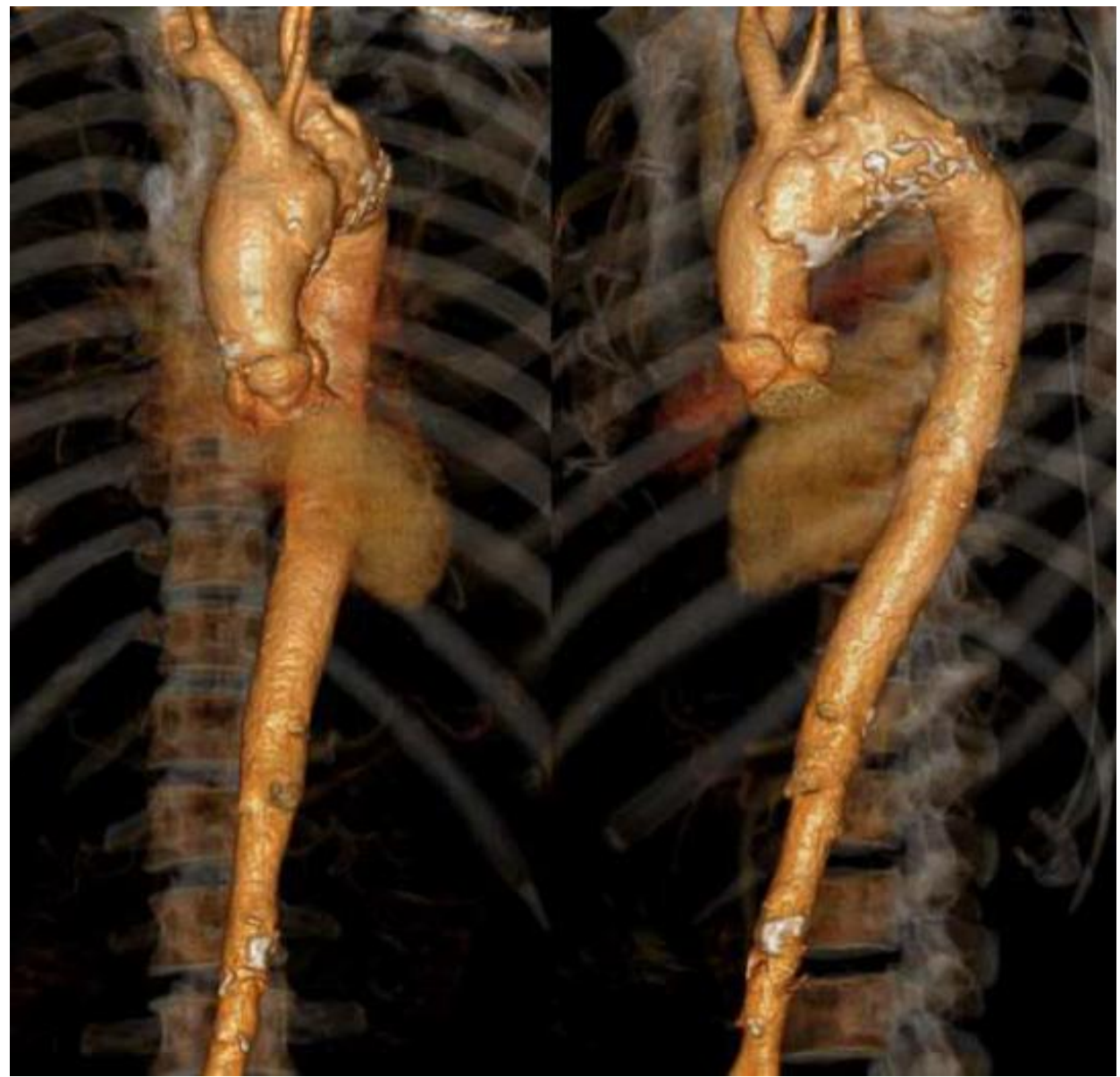

Figure-3 Computer tomography showing postoperative repaired aortic arch

\section{Discussion}

An aneurysm defined as a pathological dilatation of a segment of a blood vessel ${ }^{(1)}$. Aortic archaneurysms can present with a wide spectrum of symptoms like chest pain, heart failure, compression symptoms, haemoptysis, chest wall pulsatile swelling and many nonspecific symptoms ${ }^{(2)}$. Haemoptysis can be due to many causes, but most are associated with a chronic infectious process, such as tuberculosis and bronchiectasis $^{(3)}$. Ascending and arch aortic aneurysms can present as mediastinal mass. An 
aneurysm of the aortic arch may mimic a localized lung malignancy ${ }^{(4,5)}$ because of involvement of adjourning lung tissues. Aortic aneurysm formation can be associated with many conditions such as atherosclerosis, hypertension, smoking, congenital anomalies, familial syndromes, inflammatory disease and infections, tuberculosis and syphilis. Syphilis continues to be prevalent in both the developed and the developing countries $(6,7)$ and it is increasingly reported since 1998. Cardiovascular syphilis may occur in $11 \%$ of untreated syphilitic patients and symptoms may appear in 10 to 40 years after primary infection. In our reported case, only presenting complaint was haemoptysis. Diagnosis was arrived with the help of computer tomography of the chest and aortogram. The interesting part of the reported case is the management of pulmonary involvement of the aneurysm. Many data suggest aneurysmectomy with or without left pneumonectomy or lobectomy is the treatment for aneurysm involving lung with complications ${ }^{(8)}$. In our case intraoperative air leak from the lung with lung tissue bleed was managed with single right lung ventilation which allowed us to clear the left bronchial airway by suctioning and local haemostasis techniques. The imaging modalities were used to arrive at a diagnosis because of uncommon clinical presentation. These types of intra operative complications can be manager successfully in selected patients with satisfactory results.

Statistical nomenclature and data analysis - No Acknowledgments and Disclosures- No Grants or financial support for this study

\section{References}

1. Dzan VJ, Creager MA. Diseases of aorta. In: Kasper DL, Braunwald E, Fauci A, HauserS, Longo D, Jameson JL, editors Harrison's Principles of Internal Medicine; 16th edn. New York: McGraw-Hill; 2005:pp1481-5.
2. Fraser RS, Muller NL, Colman N, Pare PD. Mediastinal diseases. In: Synopsis of Diseases of Chest; 3rd edn. 2005; pp 87983.

3. Bidwell JL, Pachner RW. Hemoptysis: diagnosis and management. Am Fam Physician2005;72:1253-1260.

4. Sarmishtha De, Sajal De. Silent rupture of aneurysm of arch of aorta mimicking malignancy. BMJ Case Reports 2009; doi:10.1136/bcr.10.2008.1059

5. Chockalingam A, Gnanavelu G, Alagesan R. Massive aortic aneurysm presenting aschest wall swelling. Heart 2004;90:292.

6. Bappu NJ, Chakraborthy B, Bisoi A. A massive pulsatile chest wall mass. NZ Med J2006;119:1229-73.

7. Nakai M, Shimamoto M, Yamasaki F, Fujita S, Masumoto H, Yamada T, Nakajima D,Hamaji M. Surgical treatment of thoracic aortic aneurysm in patients with concomitant coronary artery disease. Jpn J Thorac Cardiovasc Surg 2005;53:8487.

8. Shimizu H, Ueda T, Kashima I, Mitsumaru A, Tsutsumi K, Enoki C, Iino Y, Koizumi K,Kawada S. Surgical treatment for a ruptured thoracic aortic aneurysm. Jpn J Thora Cardiovasc Surg 2001;49:62-66. 